\title{
Stimulation of MAPK-phosphatase 1 gene expression by glucocorticoids occurs through a tethering mechanism involving C/EBP
}

\author{
Krishan Johansson-Haque, Elanchelian Palanichamy and Sam Okret \\ Department of Biosciences and Nutrition, Karolinska Institutet, Karolinska University Hospital Huddinge, Novum, SE-141 86 Huddinge, Sweden \\ (Correspondence should be addressed to K Johansson-Haque; Email: krishan.johansson.haque@ki.se)
}

\begin{abstract}
Glucocorticoids (GCs) are known to inhibit mitogen-activated protein kinase (MAPK) signaling. This has been suggested to involve induced expression of MAPK-phosphatase 1 (DUSP1), which dephosphorylates and inactivates MAPKs. However, the mechanism for the transcriptional activation by GCs of DUSP1 or the identification of a GC-responsive region of the gene has so far not been described. To identify GC receptor (GR) binding to the human DUSP1 promoter in vivo, we used a chromatin immunoprecipitation (ChIP) assay and found GR to bind to a region $\sim-1.4 \mathrm{~kb}$ upstream of the transcription start site. Using promoter deletion constructs, we identified a GC-responsive region between position -1266 and $-1380 \mathrm{bp}$ of the DUSP1 promoter. However, no direct binding of GR to this GC-responsive region was detected in an electrophoretic mobility shift assay (EMSA). Instead, we identified binding of CCAAT/enhancer-binding protein beta $(\mathrm{C} / \mathrm{EBP} \beta)$ to a region between -1311 and $-1304 \mathrm{bp}$ of the DUSP1 promoter by EMSA and ChIP. Furthermore, mutation of the C/EBP binding site resulted in a dramatic loss of GC-inducible reporter gene expression, demonstrating the GC responsiveness of the DUSP1 gene to be located to a binding site for C/EBP in the DUSP1 promoter. Also, given that a GR mutant $\left(G_{\mathrm{LS} 7}\right)$, incapable of transactivating through $\mathrm{GC}$-responsive elements, still was able to bind to the DUSP1 gene in vivo and induce DUSP1 mRNA expression following treatment with GCs suggests the mode of GC activation to be mediated by a tethering mechanism involving the GR and the DUSP1 promoter-bound $\mathrm{C} / \mathrm{EBP} \beta$.
\end{abstract}

Journal of Molecular Endocrinology (2008) 41, 239-249

\section{Introduction}

Glucocorticoids (GCs) are lipophilic steroid hormones, synthesized and secreted by the adrenal cortex, that play important roles in metabolism, immune responses, proliferation, and differentiation by affecting gene expression. At a cellular level, GCs modulate gene expression via binding to the intracellular GC receptor (GR), which acts as a ligand-activated transcription factor (Necela \& Cidlowski 2004, Schäcke et al. 2006). Upon ligand binding, the GR translocates into the nucleus, homodimerizes, and binds to palindromic GC response elements (GREs) present in target genes, and activates transcription. In natural promoters, a synergy between the GR and other DNA-bound transcription factors in inducing transcription most often occurs. In addition, studies have shown that the GR can affect expression of target genes without directly contacting the DNA. This occurs through a protein-protein interaction between the GR and other DNA-bound transcription factors. This mechanism is usually referred to as tethering. Tethering seems to be the main mechanism by which the GR represses expression of target genes, as in the case of GC repression of proinflammatory genes controlled by nuclear factor $\kappa \mathrm{B}(\mathrm{NF}-\kappa \mathrm{B})$ and activator protein 1 ( AP-1, JUN/FOS heterodimer). However, GR tethering to other DNAbound transcription factors without the GR in itself contacting the DNA can also result in enhanced gene expression. This is the case following GR interaction with AP-1(JUN/JUN) in AP-1-controlled target genes, STAT5A-stimulated expression of the $\beta$-casein gene, and PBX1 in enhancing retinoic acid-stimulated HOXB1 expression (Teurich \& Angel 1995, Stöcklin et al. 1996, Subramaniam et al. 2003). This exemplifies that transcriptional stimulation of target genes by GR does not occur through a single mechanism.

Given that GCs are able to robustly blunt the onset and peak of an inflammatory response as well as triggering inflammatory resolution programs (Serhan et al. 2007), they belong to the most effectively used drugs to treat inflammatory diseases and immunodisorders such as asthma, rheumatoid arthritis, and autoimmune diseases (Adcock \& Caramori 2001). The therapeutic actions of GCs are mediated, in part, via transrepression by the GR of proinflammatory gene expression induced by immunoregulatory proteins

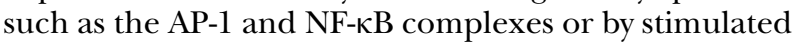

DOI: 10.1677/JME-08-0015 Online version via http://www.endocrinology-journals.org 
expression of anti-inflammatory genes such as IL10 (Clark 2007). Additionally, GCs may exert their antiinflammatory effects by inhibiting other signaling pathways that regulate inflammatory responses, such as the mitogen-activated protein kinase (MAPK) pathway (Clark \& Lasa 2003). The MAPK families, which comprise the ERKs, the JNKs, and p38 MAPKs, play an important role in the immune response by participating in the regulation of proinflammatory mediators such as cytokines and chemokines (Chang \& Karin 2001, Pearson et al. 2001).

Excessive production of proinflammatory mediators may be life-threatning, and counter-regulatory systems are needed to balance proinflammatory reactions. Hence, when the pathogenic threat is eliminated, the proinflammatory signaling cascades must be deactivated by the operation of anti-inflammatory regulators to effectively dismount the immune response and prevent undue inflammation. In mammalian cells, activated MAPKs can be inactivated by the MAPK-phosphatase 1, DUSP1, which is an archetypal member of a dualspecificity (Thr/Tyr) phosphatase family that negatively regulates MAPKs by dephosphorylation (Camps et al. 2000, Theodosiou \& Ashworth 2002). DUSP1 is induced by mitogenic stress and proinflammatory stimuli, functioning as a feedback control mechanism that governs the production of proinflammatory cytokines by limiting the activation of MAPKs (Zhao et al. 2005).

Interestingly, DUSP1 gene expression has also been shown to be enhanced by GCs and to mediate the GC inhibition of ERK, JNK, and p38 MAPKs (Kassel et al. 2001, Chen et al. 2002, Lasa et al. 2002, Engelbrecht et al. 2003). The GCinduction of DUSP1 and thus inhibition of MAPK signaling may serve as a means by which GCs control the strength and duration of transduced proinflammatory signals and regulate the production of proinflammatory cytokines. However, studies using DUSP1-deficient mice have given contradictory results regarding the requirement of GC-stimulated expression of DUSP1 in suppressing inflammatory responses in vivo (Abraham et al. 2006, Maier et al. 2007). By contrast, other biological responses seem to be dependent on the upregulation of DUSP1 by GCs. A study by Wu et al. (2005) showed that blocking DUSP1 expression by RNAi in breast epithelial cells hampered GC-mediated ERK dephosphorylation and cell survival following paclitaxelinduced cytotoxicity. Similarly, the regulation of ERK by DUSP1 is suggested to control osteoblast proliferation in response to GCs (Horsch et al. 2007). While the effect on various biological processes in vivo of DUSP1 upregulation by GCs is under intensive study, the precise mode of GC-GR action on DUSP1 gene activation has been left undetermined. At the transcriptional level, putative GREs have been described in the mouse DUSP1 promoter (Noguchi et al. 1993); however, no studies showing a functional GC-responsive region or GR occupancy at the DUSP1 promoter region have so far been published.

The objective of this study was to investigate the mechanism by which GCs induce human (h) DUSP1 gene expression and to identify the GC-responsive region within its promoter region. For this purpose, we used a chromatin immunoprecipitation (ChIP) scanning assay to determine GR binding to the hDUSP1 promoter and promoter deletions coupled to a reporter gene in transient transfection experiments to test for functional activity. Electrophoretic mobility shift assay (EMSA) was also used to study protein-DNA interactions at the GC-responsive region of the hDUSP1 promoter region.

\section{Materials and methods}

\section{Cells and growth conditions}

The human epithelial lung carcinoma cell line, A549 was obtained from ATCC (Rockville, MD, USA). The human embryonic kidney epithelial cell line, HEK293 Flp-In cells (Invitrogen), stably expressing the wild-type GR or GR mutants, $\mathrm{GR}_{\mathrm{LS} 7}$ and $\mathrm{GR}_{\mathrm{R} 488 \mathrm{O}}$, has previously been described (Bladh et al. 2005). Cells were grown at $37{ }^{\circ} \mathrm{C}$ in $5 \% \mathrm{CO}_{2}$ in medium containing $45 \% \mathrm{~F} 12$ (HAM; Gibco. BRL), 45\% DMEM (Gibco), $10 \%$ fetal bovine serum (Saveen and Werner AB, Malmö, Sweden), and penicillin/streptomycin, $10 \mathrm{IU} / \mathrm{ml}$ and $100 \mu \mathrm{g} / \mathrm{ml}$ respectively (Gibco). Stably transfected HEK293 Flp-In cells were grown in the presence of $100 \mu \mathrm{g} / \mathrm{ml}$ Hygromycin according to the instructions by the manufacturer (Invitrogen).

\section{ChIP assay}

HEK293 Flp-In cells with stably transfected GR were either treated with $1 \mu \mathrm{M}$ of the synthetic GC dexamethasone (Dex; Sigma-Aldrich) or vehicle alone for $90 \mathrm{~min}$ and were then cross-linked using formaldehyde at a final concentration of $1 \%$ for $10 \mathrm{~min}$ at room temperature. The cross-linking reaction was stopped by the addition of glycine to a final concentration of $0 \cdot 125 \mathrm{M}$ for $5 \mathrm{~min}$ in room temperature. Cells were washed with cold PBS, harvested, and resuspended in $400 \mu \mathrm{l}$ lysis buffer (50 mM HEPES-KOH (pH 8.0), $1 \mathrm{mM}$ EDTA, $0.5 \mathrm{mM}$ EGTA, $140 \mathrm{mM} \mathrm{NaCl}, 10 \%$ glycerol, $0.5 \%$ NP-40, $0 \cdot 25 \%$ Triton X-100, and $1 \mathrm{mM}$ phenylmethylsulphonyl fluoride (PMSF)) containing Complete Protease Inhibitor Cocktail (Roche) and sonicated 10 times for $10 \mathrm{~s}$. The chromatin-containing supernatants obtained after centrifugation were incubated with $1 \mu \mathrm{g}$ protein A purified monoclonal anti-GR antibody 7 (Okret et al. 1984) or $1 \mu \mathrm{g}$ of an antibody specific for C/EBP $\beta$ (sc-7962 X, Santa Cruz Biotechnology, Santa Cruz, CA, USA) overnight at $4{ }^{\circ} \mathrm{C}$. 
The following day the supernatants were transferred into new non-stick microcentrifuge tubes (Scientific Specialties Inc., Lodi, CA, USA) and incubated with $50 \mu \mathrm{l}$ protein A/G Sepharose (50\% slurry; Santa Cruz Biotechnology) under gentle agitation for $2 \mathrm{~h}$ at $4{ }^{\circ} \mathrm{C}$. The pellets were successively washed twice with $1 \mathrm{ml}$ wash buffer (10 mM Tris-HCl (pH 8.0), 1 mM EDTA, $0.5 \mathrm{mM}$ EGTA, $200 \mathrm{mM} \mathrm{NaCl}$, and $1 \mathrm{mM}$ PMSF), thrice with wash buffer with increased salt concentration (500 $\mathrm{mM} \mathrm{NaCl})$, and once with ordinary wash buffer. After washing, the pellet was resuspended in $110 \mu \mathrm{l} \mathrm{TE}$ buffer (10 mM Tris-HCl ( $\mathrm{pH} 8.0$ ) and $1 \mathrm{mM}$ EDTA) with $1 \%$ SDS and the cross-links were reversed by overnight incubation at $65^{\circ} \mathrm{C}$. Using a PCR purification kit (Promega), DNA was purified and eluted in $50 \mu \mathrm{l}$ elution buffer. DNA $(5 \mu \mathrm{l})$ was amplified by quantitative PCR using Power SYBR green PCR master mix (Applied Biosystems, Foster City, CA, USA) with primers derived from the human DUSP1 gene promoter.

\section{PCR primer sets for the ChIP assay and qRT-PCR}

Since average chromatin size post-sonication was about 400-600 bp (verified by agarose gel electrophoresis and ethidium bromide staining), PCR primers for ChIP scanning of the hDUSP1 promoter were used with a standardized sequence interval of $\sim 500 \mathrm{bp}$. The PCR primers used were as follows (numbers refer to the relative position upstream of the transcription initiation site; + 1): - 2364/-2313: forward primer 5'-CCT GAG TTC CCT AAA CCG CC-3 ${ }^{\prime}$, reverse primer $5^{\prime}$-TTG TAG ATG GTT TGA GGC CCA-3'; - 2245/ - 2193: forward primer 5'-CTG ACC ATC CAG CAG-3', reverse primer 5'-AAA GAG TGC AGA GAG-3'; - 1464/ - 1412: forward primer $5^{\prime}$-CGC AGG CGA AAA CAC ACA-3', reverse primer 5'-ACC AGT GGC AAC TTC TGC ATT-3'; $-834 /-783$ : forward primer $5^{\prime}$-TGC CTC CCT TGG CTC CA-3' ${ }^{\prime}$, reverse primer $5^{\prime}$-AAT GCT ATT CCT AGT CTT GTG GCC-3' $;-521 /-469$ : forward primer $5^{\prime}$-TCA GTT TCC CCG CCT GTT AG-3' ${ }^{\prime}$, reverse primer $5^{\prime}$-ACT CTT GTG CCC CTT TTC CTC-3'; + 94/ + 144: forward primer $5^{\prime}$-TGA CGC TCC TCT CTC AGT CCA-3' , reverse primer $5^{\prime}$-GTC TCT CTG CGC CGA ACC-3' ${ }^{\prime}$. Primers sets (forward primer $5^{\prime}$-TTC AGA AGG TCG GTT-3' , reverse primer 5'-CAT CCC TGC AAG AAC-3') selected from a sequence located $\sim 7.5 \mathrm{~kb}$ downstream of the last exon of the human DUSP1 gene served as a normalizing control. A pair of primers (forward primer 5'-GCA CAA GGC AGT CCC TGT AAT C-3', reverse primer 5'-TGC GGT GAC GTG GCC-3') encompassing a functionally characterized GRE of the p57 $7^{\mathrm{Kip} 2}$-promoter (Alheim et al. 2003) served as a positive control for GR binding when using the ChIP assay.

Quantitative real-time PCR for $\mathrm{h} D U S P 1$ mRNA expression was performed as previously described (Bladh et al. 2005).

\section{Plasmids, transient transfections, and luciferase assays}

The pGL3 basic luciferase reporter vector (Promega) with a subcloned insert harboring $\sim 3 \mathrm{~kb}$ of the hDUSP1 promoter region upstream of the transcription initiation site was a kind gift from Dr Yusen Liu (Horsch et al. 2007).

Promoter deletion constructs were made of this reporter plasmid by restriction enzyme digestion and religation. Deletions from the $5^{\prime}$ end resulted in fragments of the hDUSP1 promoter with different lengths (numbers refer to location corresponding to transcriptional start site $=+1$ ): undigested hDUSP1 promoter insert -2975 to $+247 \mathrm{bp}:-2551$ to +247 : -2078 to +247 : -1380 to +247 : -1266 to +247 : -2975 to $+247(\Delta-1380$ to -1266$)$. An oligonucleotide corresponding to a region between positions -1380 and $-1266 \mathrm{bp}$ of the $\mathrm{h}$ DUSP1 gene (114 $\left.\mathrm{bp}_{\mathrm{wt}}\right)$ and the corresponding DNA stretch carrying a mutation of a putative $\mathrm{C} / \mathrm{EBP}$ binding site $(114 \mathrm{bp}$ C/EBPmut $)$ were both obtained from DNA Technology (A/S Denmark) with 5'-SacI and 3'-BglII overhangs. After digesting the pGL3-promoter luciferase reporter vector with SacI and BglII, the oligos were cloned in sense orientation upstream of the SV40 promoter containing luciferase reporter gene. The obtained constructs were confirmed by sequencing. Plasmid transfection experiments followed the same procedure for all plasmid constructs. A549 cells, which express endogenous GR, were plated in 24-well tissue culture plates overnight with antibiotic-free growth medium (see above) and were co-transfected the following day with $200 \mathrm{ng}$ reporter plasmid construct and $50 \mathrm{ng}$ internal control CMV- $\beta$-gal per well, using FuGENE 6 transfection reagent (Roche Applied Science) according to the manufacturer's protocol. Eight hours post-transfection, cells were treated either with or without $100 \mathrm{nM}$ Dex (Sigma-Aldrich) without a change of medium. The cells were assayed for luciferase and $\beta$-galactosidase activity $24 \mathrm{~h}$ post-transfection as previously described (Bladh et al. 2005). The $\beta$-galactosidase activity of the cell lysate was used to equalize for differences in transfection efficiencies and in the amount of lysate used for each assay. All experiments were performed in triplicates and arbitrary luminescence units are here presented as fold induction $(-$ Dex $/+$ Dex treatment $)$.

\section{Nuclear extract preparation and electromobility shift assay (EMSA)}

Nuclear protein extracts were prepared from A549 cells grown to $90 \%$ confluence in a $10 \mathrm{~cm}$ tissue culture plate and treated with $100 \mathrm{nM}$ Dex for $90 \mathrm{~min}$. The cells were washed with ice-cold PBS, harvested, resuspended in 
$400 \mu \mathrm{l}$ buffer A (10 mM HEPES (pH 7.9), $10 \mathrm{mM} \mathrm{KCl,}$ $0 \cdot 1 \mathrm{mM}$ EDTA, $0 \cdot 1 \mathrm{mM}$ EGTA, $1 \mathrm{mM}$ dithiothreitol (DTT), and $0.5 \mathrm{mM}$ PMSF) containing Complete Protease Inhibitor Cocktail (Roche), and allowed to swell on ice for $15 \mathrm{~min}$. After adding Nonidet P-40 to a final concentration of $0.5 \%$, the cells were vortexed for $10 \mathrm{~s}$ followed by centrifugation at $7200 \mathrm{~g}$ for $2 \mathrm{~min}$. The pellet was resuspended in $50 \mu \mathrm{l}$ buffer B $(20 \mathrm{mM}$ HEPES (pH 7.9), $420 \mathrm{mM} \mathrm{NaCl}, 0.5 \mathrm{mM}$ EDTA, $0.5 \mathrm{mM}$ EGTA, $1 \mathrm{mM}$ DTT, and $0.5 \mathrm{mM}$ PMSF) containing protease inhibitors (Roche) and incubated on ice for $20 \mathrm{~min}$ with occasional vortexing. Nuclear proteins were isolated following centrifugation at $7200 \mathrm{~g}$ for $10 \mathrm{~min}$ and protein concentrations were determined by Bradford assay (Bio-Rad Laboratories Inc). Samples were stored at $-70{ }^{\circ} \mathrm{C}$.

EMSAs were performed as described previously (Alheim et al. 2003), with a few modifications. The probes used in the EMSA experiments (all purchased from DNA technology) were end labeled by T4 polynucleotide kinase (Invitrogen) using $\left[\gamma^{-32} \mathrm{P}\right]$ $(3000 \mathrm{Ci} / \mathrm{mmol}$ Amersham Pharmacia Biotech). In brief, $10 \mu \mathrm{g}$ nuclear extracts were incubated with $0 \cdot 1-$ $0.3 \mathrm{ng}$ of radiolabeled oligonucleotide probe for $30 \mathrm{~min}$ at room temperature in $1 \mathrm{X}$ binding buffer (2.5\% glycerol, $0 \cdot 05 \%$ Nonidet P-40, $50 \mathrm{mM} \mathrm{KCl}, 5 \mathrm{mM}$ $\mathrm{MgCl}_{2} 1 \mathrm{mM}$ EDTA, $10 \mathrm{mM}$ Tris $(\mathrm{pH} 7 \cdot 6)$ ), and $2 \mu \mathrm{g}$ poly(dI-dC) (Amerhsam) in a total volume of $20 \mu \mathrm{l}$. When indicated a 100-fold molar excess of unlabeled competitor oligonucleotide was included in the binding reaction. Protein-nucleic acid complexes were resolved using a non-denaturating polyacrylamide gel consisting of $4 \%$ acrylamide (29:1 ratio of acrylamide/ bisacrylamide) (Bio-Rad Laboratories Inc.) run in $0.25 \times$ TBE buffer for $1.5 \mathrm{~h}$ at a constant voltage of $200 \mathrm{~V}$. Oligonucleotides that were radiolabeled in this study include (shown with the upper strand sequence) the 114 bp human DUSP1 promoter fragment (corresponding to region between -1380 and $-1266 \mathrm{bp}$ of the hDUSP1 gene): 5'-CCAGCGAAATCCCCTCCCCCAGGAGGGGAGGAAACCGCAGAATGTTCCTGACTCGGCACCCGGGCGGGTGGCGCAATGTTTATGTTTGTGTACCCAGCGCGTCGCGTCGCTGCA- $3{ }^{\prime}$, the 54-82 bp subregion of the $114 \mathrm{bp}$ oligonucleotide (corresponding to region between -1326 and $-1298 \mathrm{bp}$ of the $\mathrm{h} D U S P 1$ gene), and the GRE from the tyrosine aminotransferase gene $\left(\mathrm{GRE}_{\mathrm{tat}}\right.$ : GRE underlined): 5'-ATTACTAGAACATCCTGTACAGTCGAC-3' (Alheim et al. 2003). Oligonucleotides used as cold competitor in this study include (showed with the upper strand sequence) five subregions (1-24, 20-42, 38-61, 54-82, and 19-114) of the full-length $114 \mathrm{bp}$ oligonucleotide; the $114 \mathrm{bp}$ promoter fragment itself; a heat shock response element (HSE) oligo: 5'-CTAGAAGCTTCTAGAAGCTTCTAGAA-3'; a C/EBP consensus oligo: $5^{\prime}$-TGCAGATTGCGCAATCTGCA-3'; and a 54-82 bp subregion of the $114 \mathrm{bp}$ fragment containing a mutation of the putative $\mathrm{C}$ / EBP binding site (base substitution underlined): 5'-CGGCACCGGGGCGGGCAGTGTGATGTTTA-3'. Supershift experiments were performed by preincubating samples with $1 \mu \mathrm{l}$ antibody for $1 \mathrm{~h}$ at $4{ }^{\circ} \mathrm{C}$ before application to the gel. Antibodies specific for C/EBP (sc-746 X), p50 (sc-114 X), and Sp1 (sc-59 X) were all purchased from Santa Cruz Biotechnology. EMSA experiments using the GRE $_{\text {tat }}$ probe were performed as previously described with some alterations (Alheim et al. 2003). Briefly, $0.3 \mathrm{ng}$ radiolabeled $\mathrm{GRE}_{\text {tat }}$ was incubated with $10 \mu \mathrm{g}$ crude extract containing a bacterially expressed fusion protein between the GR DNA-binding domain (DBD) and GST (kindly provided by Dr Ann-Charlotte Wikström), for $30 \mathrm{~min}$ at room temperature in a binding buffer containing $20 \mathrm{mM}$ Tris- $\mathrm{HCl}(\mathrm{pH} 8.0)$, $10 \%$ (w/v) glycerol, $1 \mathrm{mM}$ EDTA, $1 \mathrm{mM}$ DTT, $75 \mathrm{mM}$ $\mathrm{KCl}, 3 \% \mathrm{BSA}$, and $2 \mu \mathrm{g}$ poly (dI-dC). After incubation, the binding reaction was separated on a $4 \%$ polyacrylamide gel, with a constant voltage of $200 \mathrm{~V}$ in $0.25 \times$ TBE for $1.5 \mathrm{~h}$.

\section{Sequence analysis}

Identification of transcription factor binding sites was performed using the web-based algorithm CONREAL: conserved regulatory elements anchored alignment (http://conreal.niob.knaw.nl).

\section{Statistical analysis}

Values are presented as mean \pm s.D. and statistical analysis was performed using one-way ANOVA with Tukey's test as post hoc or Student's unpaired $t$-test with two-tailed distribution where appropriate. Differences were considered statistically significant when $P<0 \cdot 05$.

\section{Results}

\section{ChIP assay identifies GR binding to the hDUSP1 promoter}

In order to identify GR occupancy at the DUSP1 promoter in vivo, we performed a ChIP scanning assay surveying $\sim 3 \mathrm{~kb}$ of the human DUSP1 promoter. Given that DNA fragment size after sonication was $400-600 \mathrm{bp}$, the DUSP1 promoter was covered with a sequence interval of $\sim 500 \mathrm{bp}$ between the six sets of PCR primers used (Fig. 1A). Using this arrangement, GR binding was found to occur $\sim 1.4 \mathrm{~kb}$ upstream of the transcription start site of the human DUSP1 gene upon Dex treatment (Fig. 1A). GR binding to the DUSP1 promoter was enriched four- to six-fold upon Dex administration. The specificity of GR binding was further confirmed as no 

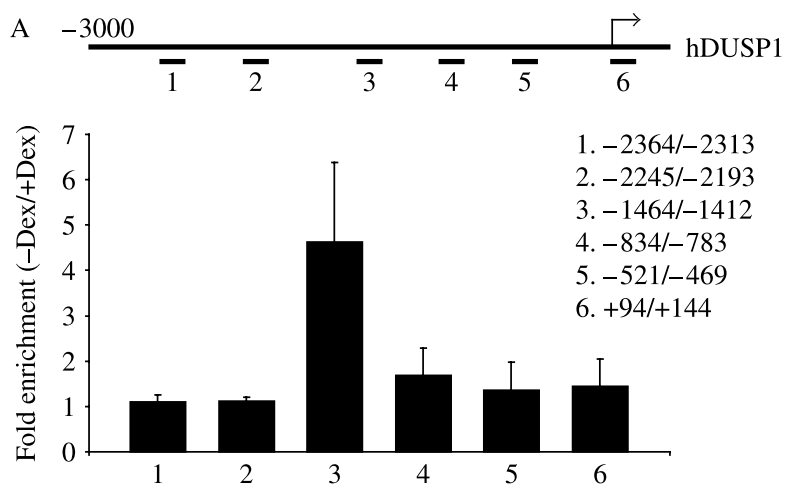

$\mathrm{B}$

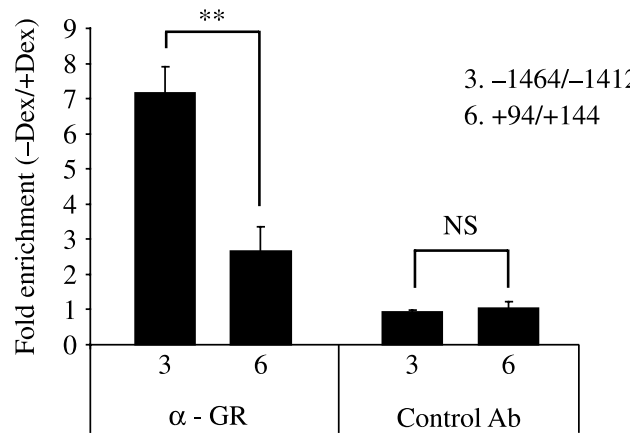

Figure 1 Mapping GR binding sites of the human DUSP1 promoter by a ChIP scanning procedure. HEK293 cells stably transfected with $\mathrm{GR}_{\mathrm{wt}}$ were treated with dexamethasone $(1 \mu \mathrm{M})$ or vehicle alone for 90 min and GR binding to the DUSP1 promoter region was surveyed by ChIP scanning. (A) The positions for the PCR primers used for amplification of the DUSP1 promoter and fold enrichment following precipitation of the cross-linked DNA using a GR-specific antibody. The fold enrichment $( \pm$ dexamethasone treatment) was determined by normalizing to an internal control corresponding to a nonresponsive region located $\sim 7.5 \mathrm{~kb}$ downstream of the last exon of the DUSP1 gene. Statistical analysis was performed by one-way ANOVA followed by Tukey's post hoc test and showed significant differences in region 3 enrichment, $\left.{ }^{* * *} P<0.001\right)$ compared with the other regions. Means \pm S.D. for $n=3-8$ experiments are shown. (B) Fold enrichment when using an isotype control antibody and PCR amplification by primer pairs 3 and 6 respectively. Statistical analysis was performed with Student's unpaired $t$-test ${ }^{* *} P<0 \cdot 01$, $\mathrm{ns}=$ non-significant). Means \pm s.D. for $n=3$ experiments are shown.

enrichment was seen following precipitation using an isotype-specific control antibody (Fig. 1B). In addition, when precipitating DNA using the GR-specific antibody from cells lacking GR, no enrichment of any DUSP1 promoter region was seen (data not shown).

\section{Defining a GC-responsive region of the hDUSP1 promoter}

To functionally identify the region responsible for GC regulation of the DUSP1 gene, we used a pGL3-basic luciferase reporter gene into which $\sim 3 \mathrm{~kb}(-2975$ to $+247 \mathrm{bp}$ ) of the human DUSP1 promoter was cloned. This as well as reporter vector constructs containing $5^{\prime}$ promoter deletion of the above construct were transfected into human A549 cells, treated with or without Dex and analyzed for luciferase activity. As shown in Fig. 2, a threefold increase in luciferase activity was seen in cells transfected with the reporter gene containing $3 \mathrm{~kb}$ of the hDUSP1 promoter following Dex treatment. Deletions of promoter regions from -2975 to $-1380 \mathrm{bp}$ had no effect on the GC responsiveness of the hDUSP1 promoter (Fig. 2). However, further deletion of the promoter to $-1266 \mathrm{bp}$ strongly decreased the GC response. This suggests that a GC-responsive region is located between -1380 and $-1266 \mathrm{bp}$ of the hDUSP1 promoter. This identified region is in agreement with the GR binding region identified by the ChIP assay (Fig. 1A). A deletion of this $114 \mathrm{bp}$ region in the context of the $3 \mathrm{~kb}$ promoter fragment resulted in a loss of the GC response (Fig. 2). In addition, the $114 \mathrm{bp}$ region alone when inserted into the pGL3 promoter vector directly upstream of the heterologous SV40 promoter was able to induce luciferase expression when stimulated with Dex, further demonstrating the importance of this region for the GC induction of the DUSP1 gene. Interestingly, sequence analysis using the CONserved Regulatory Elements anchored Alignment (CONREAL) algorithm did not reveal the presence of any GRE-like sequences within the GC-inducible 114 bp hDUSP1 promoter region. This suggests GC induction of DUSP1 to occur through a non-classical trancriptional activation mechanism independent of direct DNA binding by the GR.

\section{EMSA analysis of protein interactions with the $114 \mathrm{bp}$ GC-responsive region}

To study protein binding to the $114 \mathrm{bp}$ GC-responsive region, an EMSA was performed using nuclear extracts from A549 cells and the $114 \mathrm{bp}$ fragment as probe.

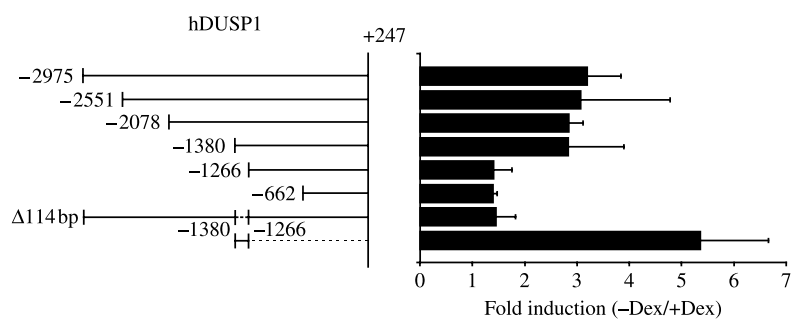

Figure 2 Identification of a GC-responsive region of the human DUSP1 promoter using promoter deletion constructs in transfection experiments. The left diagram shows the different promoter constructs used (numbers indicate bps from transcription start site). The right diagram shows the fold induction of luciferase reporter gene activity $( \pm$ dexamethasone treatment; $100 \mathrm{nM}$, $24 \mathrm{~h}$ ). Illustrated in the bottom of Fig. 2 is the region between -1380 and -1266 bp of the DUSP1 promoter cloned in sense orientation upstream of a SV40 promoter containing luciferase reporter gene (pGL3-promoter vector). Means \pm s.D. for $n=3-4$ experiments are shown. 
As can be seen in Fig. 3, two specific protein-DNA complexes were formed on the $114 \mathrm{bp}$ fragment (lane 2 ) that were competed by a 100-fold excess of unlabeled $114 \mathrm{bp}$ fragment (lane 3), but not by a 100-fold molar excess of an unrelated DNA sequence (lane 9). To determine what subregions of the $114 \mathrm{bp}$ DNA were involved in the formation of the protein-DNA complexes, the 114 bp DNA probe was competed with five subregions of the $114 \mathrm{bp}$ region. The competition experiments showed that a single subregion between 54 and $82 \mathrm{bp}$ of the $114 \mathrm{bp}$ fragment (corresponding to position -1326 to $-1298 \mathrm{bp}$ of the DUSP1 gene) competed with the full-length probe for complex formation (lane 7, lower band), suggesting this subregion to be important for protein binding to the $114 \mathrm{bp}$ hDUSP1 fragment. Moreover, the $114 \mathrm{bp}$ fragment may also bind proteins outside of the 54-82 bp subregion, since the upper complex migrates faster upon competition with this subregion. This is most likely due to a loss of protein(s) binding selectively to the 54-82 bp subregion while protein(s) binding outside of this region remain bound.

\section{GC responsiveness is located to a binding site for C/EBP}

Further sequence analysis (CONREAL) of the 54-82 bp subregion of the $114 \mathrm{bp}$ fragment revealed a binding

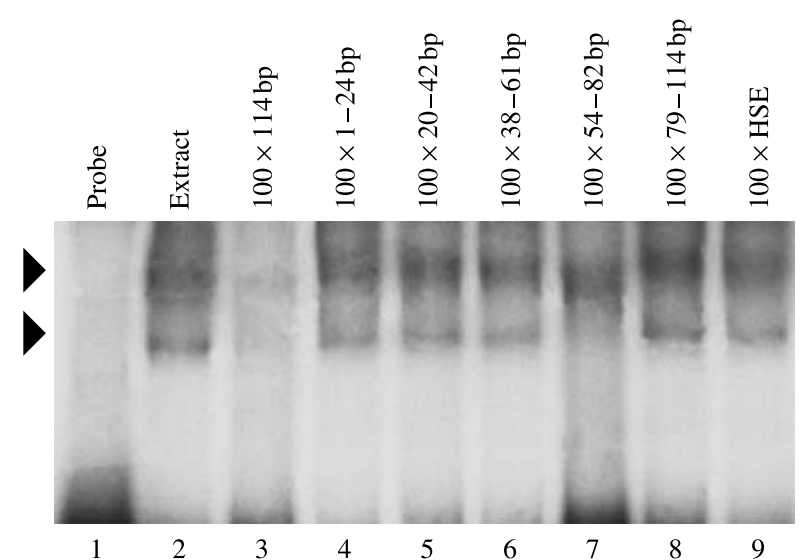

Figure 3 The $54-82$ bp subregion $(-1326$ to -1298 bp of the DUSP1 promoter) of the GC-responsive $114 \mathrm{bp}$ sequence $(-1380$ to $-1266 \mathrm{bp})$ is responsible for specific protein-DNA complexes formed on the 114 bp region. Lane 1 is the ${ }^{32} \mathrm{P}$-labeled $114 \mathrm{bp}$ fragment probe alone. Lanes $2-9$, nuclear extract prepared from dexamethasone-treated A549 cells incubated with the 114 bp probe. Lanes 3-9, competition of the complexes formed with the $114 \mathrm{bp}$ probe with a 100 -fold molar excess of unlabeled oligonucleotides. Lane 3 , the whole 114 bp fragment; lane 4, subregions 1-24; lane 5, 20-42; lane 6, 38-61; lane 7, 54-82; and lane 8, 79-114 of the 114 bp fragment. Lane 9 is competition with a 100 -fold molar excess of an oligonucleotide (HSE) encompassing a consensus binding site for heat shock factor-1. Arrows represent specific protein-DNA complexes. One representative experiment out of three performed is shown. site for $\mathrm{C} / \mathrm{EBP}$, located between position -1311 and $-1304 \mathrm{bp}$ of the DUSP1 promoter (Fig. 4A). In addition, this $\mathrm{C} / \mathrm{EBP} \alpha$ binding site, as well as its relative location upstream of the transcription start site of the DUSP1 gene, is highly conserved in the DUSP1 promoter from several species, implicating a functional relevance of this region.

In order to investigate whether the 54-82 bp subregion of the $114 \mathrm{bp}$ sequence indeed interacted with $\mathrm{C} / \mathrm{EBP}$, the subfragment was radiolabeled and used as probe in an EMSA using an unlabeled C/EBP consensus oligonucleotide as competitor. As can be seen in Fig. 4B, complex formations on the 54-82 bp subregion were abolished when using a C/EBP consensus oligonucleotide as competitor (lane 5) as well as when competing with an excess of unlabeled wild-type 54-82 subregion oligonucleotide (lane 3). By contrast, no competition for complex formation was seen when competing with a 100 -fold molar excess of the 54-82 bp fragment containing a mutation of the putative C/EBP binding site (lane 6) or an oligonucleotide (HSE) containing a consensus binding site for the heat shock factor-1 (lane 4). This demonstrates the requirement of an intact $\mathrm{C} / \mathrm{EBP}$ binding sequence in the 54-82 bp subregion for formation of the specific protein-DNA complexes. EMSA experiments using a $\mathrm{C} / \mathrm{EBP} \beta$ antibody resulted in loss of protein-DNA interactions (lane 7), demonstrating the presence of $\mathrm{C} / \mathrm{EBP}$ in the complexes. No supershift and only a minor loss of complexes formed were seen when using antibodies directed against the p50 component of NF$\kappa \mathrm{B}$ or the Sp1 transcription factor (lanes 8 and 9 respectively), showing the specificity in the $\mathrm{C} / \mathrm{EBP} \beta$ antibody shift.

In order to confirm binding of $\mathrm{C} / \mathrm{EBP} \beta$ to the DUSP1 promoter in vivo, we performed a ChIP assay on A549 cells using an antibody targeting $\mathrm{C} / \mathrm{EBP} \beta$. As is the case for GR binding, the $-1.4 \mathrm{~kb}$ region of the DUSP1 promoter is also selectively enriched using the $\mathrm{C} / \mathrm{EBP} \beta$-specific antibody, whereas no enrichment of this region is seen using a non-specific antibody control (Fig. 4C). This is in line with the results from the EMSA and confirms $\mathrm{C} / \mathrm{EBP} \beta$ binding to the DUSP1 promoter.

To functionally test the identified C/EBP binding site for involvement in the GC stimulation, a $114 \mathrm{bp}$ hDUSP1 promoter fragment containing a mutation of the $\mathrm{C} / \mathrm{EBP}$ binding site was examined in a luciferasebased reporter assay. Mutation of this site resulted in a dramatic loss of the ability of the $114 \mathrm{bp}$ fragment to induce luciferase gene expression following Dex treatment (Fig. 4D). This result clearly suggests that the DUSP1 regulation by activated GR requires functional binding of $\mathrm{C} / \mathrm{EBP} \beta$ to a conserved $\mathrm{C} / \mathrm{EBP}$ site located between position -1311 and $-1304 \mathrm{bp}$ of the DUSP1 promoter. 
A

$$
\begin{aligned}
& \text { Human } \\
& \text { Chimp } \\
& \text { Mouse } \\
& \text { Rat }
\end{aligned}
$$

B

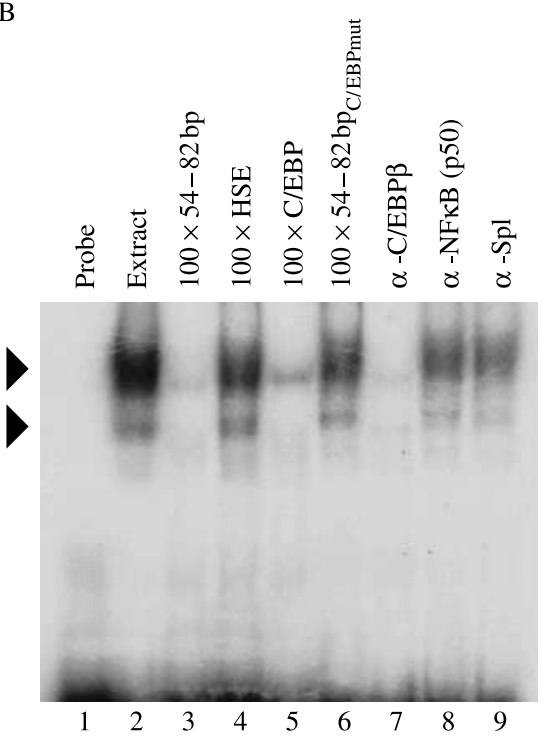

C
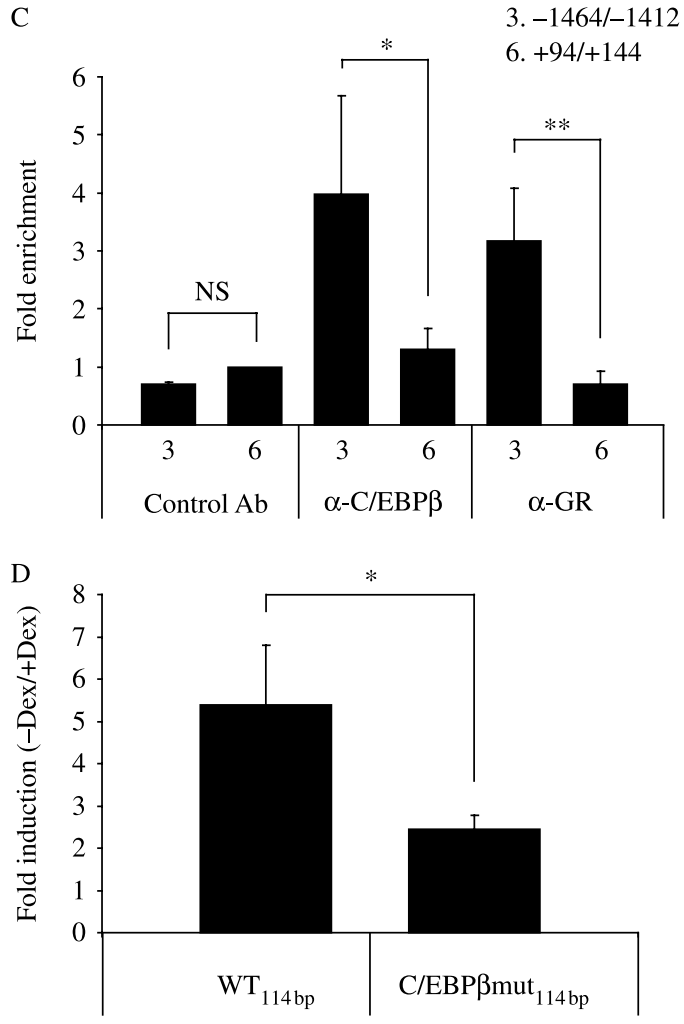

No direct GR binding to the 114 bp GC-responsive region

As mentioned above, no GRE-like sequences were found in the GC-inducible $114 \mathrm{bp}$ DUSP1 promoter region. In order to confirm lack of direct GR binding to this element, we performed an EMSA where a probe containing a classical GRE from the tyrosine aminotransferase $\left(\mathrm{GRE}_{\mathrm{tat}}\right)$ gene promoter was incubated with bacterially expressed GR-DBD protein and competed with the $114 \mathrm{bp}$ region. As can be seen in Fig. 5A, formation of $\mathrm{GRE}_{\mathrm{tat}}$-GR complex was abolished when competing with an excess of unlabeled $\mathrm{GRE}_{\text {tat }}$ oligonucleotide (lane 3). However, no competition was seen when an excess of unlabeled $114 \mathrm{bp}$ fragment (lane 4) or the 114 bp subregions 54-82 bp (lane 6) was used as competitor. This demonstrated that no direct GR binding occurs to the GC-responsive $114 \mathrm{bp}$ region of the DUSP1 promoter. Instead, this suggests that

Figure $4 \mathrm{~A}$ conserved binding site for CCAAT/enhancer-binding protein (C/EBP) of the 114 bp DUSP1 fragment is important for $\mathrm{GC}$ regulation. (A) Alignment and comparison of DUSP1 promoter regions from different species corresponding to the -1326 to -1298 region of the hDUSP1 promoter. The conserved C/EBP site is underlined. (B) EMSA demonstrates binding of C/EBP to subregions $54-82$ of the 114 bp fragment. Lane 1 is free ${ }^{32}$ P-labeled 54-82 bp oligonucleotide probe. Lanes 2-9, nuclear extract prepared from dexamethasone-treated A549 cells incubated with 54-82 bp probe. Lanes 3-6, competition of the complexes formed with the 54-82 bp probe with a 100-fold molar excess of unlabeled oligonucleotides. Lane 3, the 54-82 bp fragment; lane 4, HSE consensus; lane 5, C/EBP consensus; and lane $6,54-82$ bp subregion with a mutation of the putative C/EBP binding site. Lanes 7-9, supershift experiments of complex-bound 54-82 bp probe. Lane 7, C/EBP $\beta$ antibody; lane 8, NF-кB (p50) antibody; and lane 9, Sp-1 antibody. Arrows represent specific protein-DNA complexes. One representative experiment out of three performed is shown. (C) ChIP analysis of C/EBP $\beta$ and GR binding to the $-1.4 \mathrm{~kb}$ region of the hDUSP1 promoter in A549 cells in vivo. Fold enrichment in dexamethasone-treated A549 cells when using a control antibody or a C/EBP $\beta$ antibody and PCR amplification by primer pairs 3 and 6 respectively (first four bars from the left). Enrichment of primer pair 6 for the control antibody was given the nominal value 1 in each experiment and the results for the other conditions are presented relative to this nominal value. Fold enrichment ( \pm dexamethasone treatment) and PCR amplification by primer pairs 3 and 6 respectively, when using a GR antibody is seen in the last two bars. The fold enrichment was determined by normalizing to an internal control corresponding to a non-responsive region located $\sim 7.5 \mathrm{~kb}$ downstream of the last exon of the DUSP1 gene. Statistical analysis was performed with Student's unpaired $t$-test ${ }^{\star} P<0.05$, ${ }^{* \star} P<0 \cdot 01$, ns $=$ non-significant). Means \pm S.D. for $n=3$ experiments are shown. (D) Mutation of the C/EBP binding site of the $114 \mathrm{bp}$ hDUSP1 promoter fragment results in a significant loss of reporter gene expression. A549 cells were transfected with the pGL3-promoter luciferase vector with either the wild-type $114 \mathrm{bp}$ hDUSP1 promoter fragment inserted or the corresponding region with a mutation of the C/EBP binding site, and thereafter treated with $100 \mathrm{nM}$ dexamethasone for $24 \mathrm{~h}$. Results are shown as fold induction ( \pm dexamethasone treatment). Statistical analysis was performed with Student's unpaired $t$-test $\left({ }^{\star} P<0 \cdot 05\right)$. Means \pm s.D. for $n=3$ experiments are shown. 
upregulation of DUSP1 gene expression by GCs is more likely to occur through a tethering between the GR and the promoter-bound $\mathrm{C} / \mathrm{EBP} \beta$ protein. We obtained further evidence for such a mechanism, since HEK293 cells containing a GR mutant $\left(\mathrm{GR}_{\mathrm{LS}}\right)$, which is unable
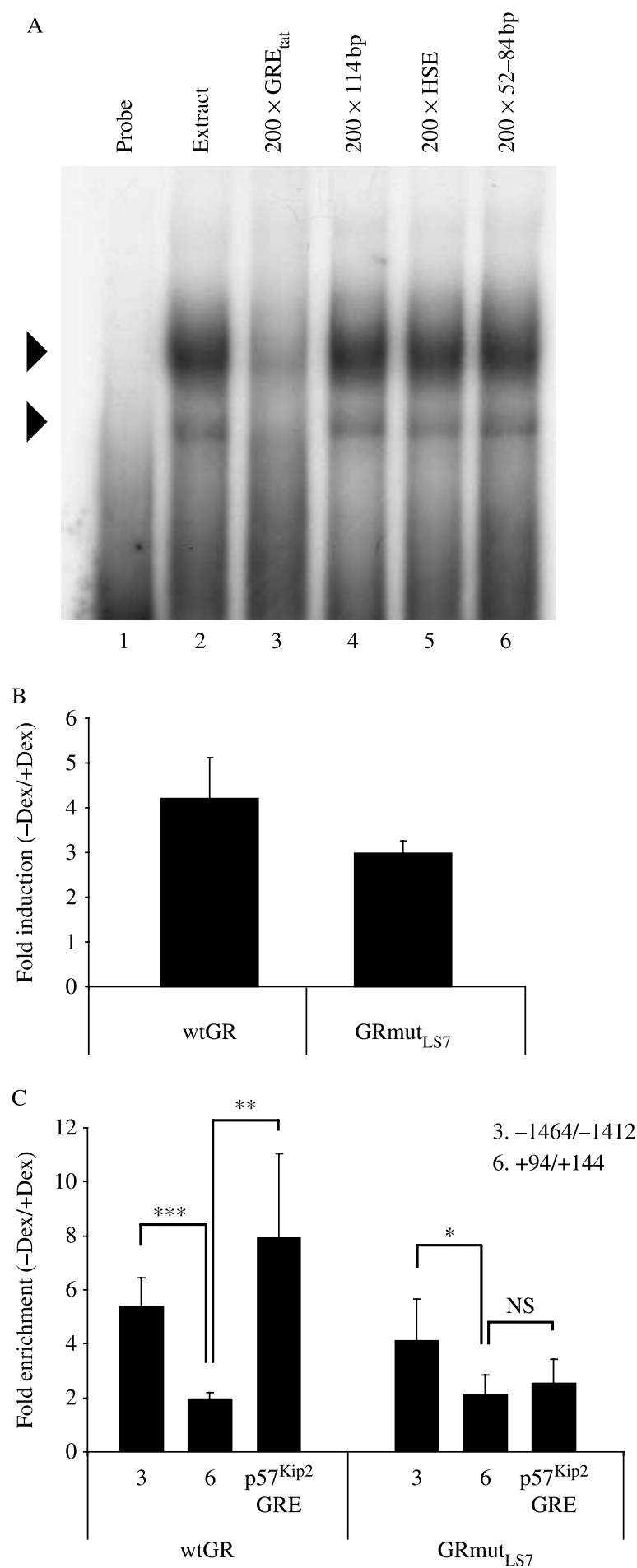

to stimulate expression from a classical GRE containing gene (Lidén et al. 1997), still was able to induce expression of the DUSP1 gene as analyzed by qRT-PCR (Fig. 5B). The ability of the $\mathrm{GR}_{\mathrm{LS} 7}$ mutant to interact with the DUSP1 gene in vivo was confirmed by a ChIP assay, demonstrating enrichment to the $-1.4 \mathrm{~kb}$ region of the DUSP1 gene as for the $\mathrm{GR}_{\mathrm{wt}}$ (Fig. 5C). However, no enrichment of binding of $\mathrm{GR}_{\mathrm{LS} 7}$ occurred in vivo to the previously described GRE containing promoter region of the GC-inducible $p 57^{K i p 2}$ gene, in contrast to the $\mathrm{GR}_{\mathrm{wt}}$ (Fig. 5C and (Alheim et al. 2003)).

\section{Discussion}

It is well established that GCs induce expression of the MAPK inhibitor, DUSP1 (Chen et al. 2002, Lasa et al. 2002, Engelbrecht et al. 2003). However, reported mechanisms of GR-mediated induction of DUSP1 gene expression have so far been unclear or contradictory. As an example, a study using transiently transfected COS-7 cells showed that a dimerization-deficient mutant of GR $\left(\mathrm{GR}^{\mathrm{dim}}\right)$, in contrast to the wild-type receptor, was unable to induce a reporter construct containing $1 \cdot 7 \mathrm{~kb}$ of the mouse Duspl promoter region, suggesting that the GR activates Duspl expression as a conventional homodimer (Kassel et al. 2001). However, in primary macrophages derived from mice expressing the $\mathrm{GR}^{\mathrm{dim} / \mathrm{dim}}, \mathrm{GC}$ stimulation still induced endogenous Dusp1 expression (Abraham et al. 2006), suggesting that GR may function as a monomer in inducing this gene. Furthermore, the previously described putative GREs of the mouse Duspl promoter sequence

Figure 5 The GR does not bind directly to the GC-responsive $114 \mathrm{bp}$ DUSP1 promoter region. (A) The GC-responsive $114 \mathrm{bp}$ hDUSP1 fragment does not compete for GR binding to a classical GRE from the amino tyrosine amino transferase gene. Lane 1 is free ${ }^{32} \mathrm{P}$-labeled $\mathrm{GRE}_{\text {tat }}$ oligonucleotide probe. Lanes 2-5, the probe is incubated with bacterially expressed GR-DBD. Lanes 36 , competition of the GR-DBD-GRE tat complex with a 200-fold molar excess of unlabeled oligonucleotides. Lane $3, \mathrm{GRE}_{\text {tat }}$; lane 4, 114 bp hDUSP1 fragment; lane 5, HSE consensus; and lane 6, 54-82 bp subregion of the $114 \mathrm{bp}$ fragment. Arrows represent specific protein-DNA complexes. The upper complex represents dimer binding of GR-DBD to the $\mathrm{GRE}_{\text {tat }}$ and the lower band monomer binding (Tsai et al. 1988). One representative experiment out of three performed is shown. (B) A GR mutant $\left(G_{L S 7}\right)$, unable to stimulate expression from a classical GRE containing gene, still induces DUSP1 mRNA expression in stably transfected HEK293 cells following dexamethasone treatment (100 nM, $24 \mathrm{~h}$ ). DUSP1 mRNA expression is determined by qPCR and results are shown as fold induction ( \pm dexamethasone treatment). The mean of three experiments \pm S.D. is shown. (C) ChIP assay demonstrates the ability of the GR mutant, $\mathrm{GR}_{\mathrm{LS} 7}$, to bind to the DUSP1 gene in vivo but not to a functionally characterized GRE of the p57 $57^{\mathrm{Kip} 2}$ gene promoter (Alheim et al. 2003). Statistical analysis was performed with Student's unpaired $t$-test $\left({ }^{\star} P<0.05,{ }^{\star \star} P<0.01, \mathrm{~ns}=\right.$ non-significant). Means \pm s.D. for $n=3-5$ experiments are shown. 
(Noguchi et al. 1993) were not functionally tested. In this study, we have demonstrated GR binding in vivo to the $\mathrm{h} D U S P 1$ gene using a ChIP scanning assay and found it to be located $\sim-1.4 \mathrm{~kb}$ upstream of the transcription initiation site. We demonstrated, using promoter deletions, a region between position -1380 and $-1266 \mathrm{bp}$ upstream of the transcription start site to be responsible for the GC induction of the DUSP1 gene. Furthermore, this $114 \mathrm{bp}$ region was functional on a heterologous promoter in inducing expression of the reporter gene upon Dex stimulation. However, sequence analysis did not reveal the presence of any GREs or GRE-like sequences embedded within this region. The inability of this region to compete for GR binding to a classical GRE (Fig. 5A) confirmed the lack of direct GR binding. Instead, a binding site for $\mathrm{C} / \mathrm{EBP} \beta$ located within this region (position -1311 to $-1304 \mathrm{bp}$ ) was identified by EMSA and positively confirmed to mediate the GC induction in reporter gene-based transfection experiments. Binding of $\mathrm{C} / \mathrm{EBP} \beta$ in vivo to the $\sim-1.4 \mathrm{~kb}$ region of the DUSP1 promoter was confirmed by a ChIP assay. The $\mathrm{C} / \mathrm{EBP}$ binding site as well as its relative location upstream of the transcription start site is evolutionarily conserved between DUSP1 promoters among several species, supporting its functional relevance. This suggests the mode of transactivation by activated GR of the DUSP1 gene to involve a positive tethering mechanism between the GR and $\mathrm{C} / \mathrm{EBP} \beta$. Additional support for such a mechanism was obtained using a GR mutant $\left(\mathrm{GR}_{\mathrm{LS} 7}\right)$ harboring a point mutation in the second zinc finger of the DBD. This GR mutant is unable to transactivate through classical GREs (Lidén et al. 1997) but still was capable to induce DUSP1 expression, similar to what was shown by Abraham et al. (2006) using the $\mathrm{GR}^{\mathrm{dim}}$ mutant. By contrast, a second GR-DBD mutant $\left(\mathrm{GR}_{\mathrm{R} 488 \mathrm{Q}}\right)$ able to repress NF- $\kappa \mathrm{B}$ activity after tumor necrosis factor- $\alpha$ stimulation (Bladh et al. manuscript submitted) did not induce DUSP1 gene expression or bind to the gene in vivo (data not shown), showing that subtle changes in the GR-DBD will differentially affect protein-protein interactions involved in tethering. The differential characteristics of the $\mathrm{GR}_{\mathrm{LS7}}$ and $\mathrm{GR}_{\mathrm{R} 488 \mathrm{Q}}$ in their binding to the DUSP1 promoter may be the result of alteration in conformation leading to differences in interaction directly with the $\mathrm{C} / \mathrm{EBP} \beta$ protein or recruitment of additional proteins required for efficient transcriptional initiation.

Based on our results, we conclude that GC induction of the DUSP1 gene is mediated via a tethering mechanism between GR and promoter-bound $\mathrm{C} / \mathrm{EBP} \beta$ at position -1311 to $-1304 \mathrm{bp}$ of the DUSP1 promoter, although it cannot be excluded that other parts outside the surveyed $3 \mathrm{~kb}$ region promoter may contribute to the GC regulation of DUSP1 expression. The observation that mutation of the identified C/EBP binding site of the DUSP1 promoter resulted in a dramatic but not complete loss of reporter gene expression (Fig. 4D) could imply a contributing role of other transcription factors in addition to $\mathrm{C} / \mathrm{EBP}$ in the GR-mediated induction of DUSP1 expression.

Interestingly, other studies have previously demonstrated a functional link between the GR and C/EBPs at the trancriptional level. In a more genome-wide screening using ChIP assay, So et al. (2007) identified enrichment of sequence motifs resembling binding sites of certain transcription factors, including $\mathrm{C} / \mathrm{EBP}$, within regions encompassing GR binding compared with regions where no GR binding was detected. In addition, Phuc Le et al. (2005) described motifs resembling C/EBP binding sites close to certain mouse GREs and showed that almost $50 \%$ of them indeed bind C/EBP $\beta$. Similar to the results presented in this study, Boruk et al. (1998) localized GC responsiveness to a binding site for $\mathrm{C} / \mathrm{EBP}$ of the herpes simplex thymidine kinase promoter. In this particular study, GR specifically enhanced the activation of transcription by the $\mathrm{C} / \mathrm{EBP} \beta$ isoform. Another study, indicating similar linkage, defined a GC-responsive region within the promoter of the $p 21^{\text {Cipl }}$ gene that contains a putative binding site for $\mathrm{C} / \mathrm{EBP} \alpha$ (Cram et al. 1998). Site-directed mutation of the $\mathrm{p} 21^{\mathrm{Cip} 1}$ promoter revealed Dex stimulation of $\mathrm{p} 21^{\mathrm{Cip} 1}$ promoter activity to be dependent on the $\mathrm{C} / \mathrm{EBP}$ binding site. Both studies clearly demonstrate that GR may potentiate trancriptional activation of target genes via $\mathrm{C} / \mathrm{EBPs}$ bound to $\mathrm{C} /$ EBP-binding sites. Furthermore, the GR can physically interact with all isoforms of $\mathrm{C} / \mathrm{EBP}$ (i.e., $\alpha,-\beta$, and $\delta$ ) (Boruk et al. 1998). Although we demonstrated an abolishment of a DNA-protein complex encompassing the C/EBP site of the DUSP1 promoter using an anti$\mathrm{C} / \mathrm{EBP} \beta$ antibody, as well as binding in vivo to the $-1.4 \mathrm{~kb}$ region of the DUSP1 promoter in ChIP assay, we cannot with certainty prove the $\mathrm{C} / \mathrm{EBP} \beta$ to be the only $\mathrm{C} / \mathrm{EBP}$ isoform to bind to this region in vivo in A549 cells. This is due to some minor cross-reactivity of the antibody with $\mathrm{C} / \mathrm{EBP} \alpha$ and $\mathrm{C} / \mathrm{EBP} \delta$ respectively. However, as $\mathrm{C} / \mathrm{EBP} \beta$ is the predominantly expressed form of C/EBP in A549 cells (Cassel et al. 2000), it is most likely that the activated GR interacts with this isoform to mediate the GC-stimulated transcription of the DUSPI gene. In line with the binding of $\mathrm{C} / \mathrm{EBP} \beta$ to the DUSP1 gene, $\mathrm{C} / \mathrm{EBP} \beta^{-/-}$ hepatocytes show reduced expression of the DUSP1 gene (Greenbaum et al. 1998).

In addition to the $\mathrm{C} / \mathrm{EBP}$ transcription factors, the GR through protein-protein interactions synergizes with several other transcription factor families to enhance target gene expression independent of direct DNA binding by the receptor. For example, GCs enhance prolactin-stimulated transcription of the $\beta$-casein gene via a functional tethering between GR and promoter-bound STAT5A (Stöcklin et al. 1996). 
Additionally, transactivation of AP-1 dependent target genes by JUN/JUN homodimers is enhanced by the activated GR (Teurich \& Angel 1995), and a report published by us showed that GCs potentiate retinoic acid-induced expression of the murine Hoxb1 gene in P19 embryonal carcinoma cells through an interaction with PBX1 without the GR contacting the DNA (Subramaniam et al. 2003). Furthermore, the ability of nuclear receptors to activate target genes through other proteins without itself physically contacting the DNA is not unique for the GR. For example, the progesterone receptor has been shown to transactivate the $p 21^{\text {Cipl }}$ gene by interacting with promoter-bound Sp1 (Owen et al. 1998) and the estrogen receptor may activate genes via protein-protein interactions with AP-1 (JUN/ FOS) and Sp1 (Sun et al. 1998, Kushner et al. 2000). Interestingly, tethering by the GR, as well as other nuclear receptors with other transcription factors bound to DNA result in either positive or negative regulation of target genes, but the precise mechanisms leading to a certain outcome is still very much unclear. Furthermore, the percentage of target genes upregulated by GR through tethering is not known. However, using GR mutants unable to induce from classical GREs in gene expression profiling experiments suggest that a significant number of GC-regulated genes may be activated through such a mechanism (Rogatsky et al. 2003). That GC induction of target genes occurs through several mechanisms may complicate the development of new GCs that dissociate between transactivation and repression of target genes.

\section{Declaration of interest}

The authors declare that there is no conflict of interest that could be perceived as prejudicing the impartiality of the research reported.

\section{Funding}

This work was supported by grants from the Swedish Cancer Society and The Swedish Research Council to S O.

\section{Acknowledgements}

We thank Dr Yusen Liu for kindly providing the DUSP1 promoterluciferase reporter gene.

\section{References}

Abraham SM, Lawrence T, Kleiman A, Warden P, Medghalchi M, Tuckermann J, Saklatvala J \& Clark AR 2006 Antiinflammatory effects of dexamethasone are partly dependent on induction of dual specificity phosphatase 1. Journal of Experimental Medicine $\mathbf{2 0 3}$ 1883-1889.
Adcock IM \& Caramori G 2001 Cross-talk between pro-inflammatory transcription factors and glucocorticoids. Immunology and Cell Biology 79 376-384.

Alheim K, Corness J, Samuelsson MK, Bladh LG, Murata T, Nilsson T \& Okret S 2003 Identification of a functional glucocorticoid response element in the promoter of the cyclin-dependent kinase inhibitor p57Kip2. Journal of Molecular Endocrinology 30 359-368.

Bladh LG, Lidén J, Dahlman-Wright K, Reimers M, Nilsson S \& Okret S 2005 Identification of endogenous glucocorticoid repressed genes differentially regulated by a glucocorticoid receptor mutant able to separate between nuclear factor- $\kappa \mathrm{B}$ and activator protein-1 repression. Molecular Pharmacology 67 815-826.

Boruk M, Savory JG \& Haché RJ 1998 AF-2-dependent potentiation of CCAAT enhancer binding protein beta-mediated transcriptional activation by glucocorticoid receptor. Molecular Endocrinology 12 1749-1763.

Camps M, Nichols A \& Arkinstall S 2000 Dual specificity phosphatases: a gene family for control of MAP kinase function. FASEB Journal 14 6-16.

Cassel TN, Nordlund-Möller L, Andersson O, Gustafsson JÅ \& Nord M $2000 \mathrm{C} / \mathrm{EBP} \alpha$ and $\mathrm{C} / \mathrm{EBP} \delta$ activate the clara cell secretory protein gene through interaction with two adjacent C/EBP-binding sites. American Journal of Respiratory Cell and Molecular Biology 22 469-480.

Chang L \& Karin M 2001 Mammalian MAP kinase signalling cascades. Nature 410 37-40.

Chen P, Li J, Barnes J, Kokkonen GC, Lee JC \& Liu Y 2002 Restraint of proinflammatory cytokine biosynthesis by mitogen-activated protein kinase phosphatase-1 in lipopolysaccharide-stimulated macrophages. Journal of Immunology 169 6408-6416.

Clark AR 2007 Anti-inflammatory functions of glucocorticoid-induced genes. Molecular and Cellular Endocrinology 275 79-97.

Clark AR \& Lasa M 2003 Crosstalk between glucocorticoids and mitogen-activated protein kinase signalling pathways. Current Opinion in Pharmacology 3 404-411.

Cram EJ, Ramos RA, Wang EC, Cha HH, Nishio Y \& Firestone GL 1998 Role of the CCAAT/enhancer binding protein-alpha transcription factor in the glucocorticoid stimulation of p21waf1/cip1 gene promoter activity in growth-arrested rat hepatoma cells. Journal of Biological Chemistry 273 2008-2014.

Engelbrecht Y, de Wet H, Horsch K, Langeveldt CR, Hough FS \& Hulley PA 2003 Glucocorticoids induce rapid up-regulation of mitogenactivated protein kinase phosphatase-1 and dephosphorylation of extracellular signal-regulated kinase and impair proliferation in human and mouse osteoblast cell lines. Endocrinology 144 412-422.

Greenbaum LE, Li W, Cressman DE, Peng Y, Ciliberto G, Poli V \& Taub R 1998 CCAAT enhancer- binding protein beta is required for normal hepatocyte proliferation in mice after partial hepatectomy. Journal of Clinical Investigation 102 996-1007.

Horsch K, de Wet H, Schuurmans MM, Allie-Reid F, Cato AC, Cunningham J, Burrin JM, Hough FS \& Hulley PA 2007 Mitogenactivated protein kinase phosphatase 1 /dual specificity phosphatase 1 mediates glucocorticoid inhibition of osteoblast proliferation. Molecular Endocrinology 21 2929-2940.

Kassel O, Sancono A, Kratzschmar J, Kreft B, Stassen M \& Cato AC 2001 Glucocorticoids inhibit MAP kinase via increased expression and decreased degradation of MKP-1. EMBO Journal 20 7108-7116.

Kushner PJ, Agard DA, Greene GL, Scanlan TS, Shiau AK, Uht RM \& Webb P 2000 Estrogen receptor pathways to AP-1. Journal of Steroid Biochemistry and Molecular Biology 74 311-317.

Lasa M, Abraham SM, Boucheron C, Saklatvala J \& Clark AR 2002 Dexamethasone causes sustained expression of mitogen-activated protein kinase (MAPK) phosphatase 1 and phosphatase-mediated inhibition of MAPK p38. Molecular and Cellular Biology 22 7802-7811.

Lidén J, Delaunay F, Rafter I, Gustafsson JÅ \& Okret S 1997 A new function for the C-terminal zinc finger of the glucocorticoid receptor. Repression of RelA transactivation. Journal of Biological Chemistry 272 21467-21472. 
Maier JV, Brema S, Tuckermann J, Herzer U, Klein M, Stassen M, Moorthy A \& Cato AC 2007 Dual specificity phosphatase 1 knockout mice show enhanced susceptibility to anaphylaxis but are sensitive to glucocorticoids. Molecular Endocrinology 21 2663-2671.

Necela BM \& Cidlowski JA 2004 Mechanisms of glucocorticoid receptor action in noninflammatory and inflammatory cells. Proceedings of the American Thoracic Society 1 239-246.

Noguchi T, Metz R, Chen L, Mattei MG, Carrasco D \& Bravo R 1993 Structure, mapping, and expression of erp, a growth factorinducible gene encoding a nontransmembrane protein tyrosine phosphatase, and effect of ERP on cell growth. Molecular and Cellular Biology 13 5195-5205.

Okret S, Wikström AC, Wrange Ö, Andersson B \& Gustafsson JÅ 1984 Monoclonal antibodies against the rat liver glucocorticoid receptor. PNAS 81 1609-1613.

Owen GI, Richer JK, Tung L, Takimoto G \& Horwitz KB 1998 Progesterone regulates transcription of the p21(WAF1) cyclindependent kinase inhibitor gene through Sp1 and CBP/p300. Journal of Biological Chemistry 273 10696-10701.

Pearson G, Robinson F, Beers Gibson T, Xu BE, Karandikar M, Berman K \& Cobb MH 2001 Mitogen-activated protein (MAP) kinase pathways: regulation and physiological functions. Endocrine Reviews 22 153-183.

Phuc Le P, Friedman JR, Schug J, Brestelli JE, Parker JB, Bochkis IM \& Kaestner KH 2005 Glucocorticoid receptor-dependent gene regulatory networks. PLoS Genetics 1 e16.

Rogatsky I, Wang JC, Derynck MK, Nonaka DF, Khodabakhsh DB, Haqq CM, Darimont BD, Garabedian MJ \& Yamamoto KR 2003 Target-specific utilization of transcriptional regulatory surfaces by the glucocorticoid receptor. PNAS 100 13845-13850.

Schäcke H, Rehwinkel H, Asadullah K \& Cato AC 2006 Insight into the molecular mechanisms of glucocorticoid receptor action promotes identification of novel ligands with an improved therapeutic index. Experimental Dermatology 15 565-573.

Serhan CN, Brain SD, Buckley CD, Gilroy DW, Haslett C, O'Neill LA, Perretti M, Rossi AG \& Wallace JL 2007 Resolution of inflammation: state of the art, definitions and terms. FASEB Journal 21 325-332.
So AY, Chaivorapol C, Bolton EC, Li H \& Yamamoto KR 2007 Determinants of cell- and gene-specific transcriptional regulation by the glucocorticoid receptor. PLoS Genetics 3 e94.

Stöcklin E, Wissler M, Gouilleux F \& Groner B 1996 Functional interactions between Stat 5 and the glucocorticoid receptor. Nature 383 726-728.

Subramaniam N, Campión J, Rafter I \& Okret S 2003 Cross-talk between glucocorticoid and retinoic acid signals involving glucocorticoid receptor interaction with the homoeodomain protein Pbx1. Biochemical Journal 370 1087-1095.

Sun G, Porter W \& Safe S 1998 Estrogen-induced retinoic acid receptor alpha 1 gene expression: role of estrogen receptor-Sp1 complex. Molecular Endocrinology 12 882-890.

Teurich S \& Angel P 1995 The glucocorticoid receptor synergizes with Jun homodimers to activate AP-1-regulated promoters lacking GR binding sites. Chemical Senses 20 251-255.

Theodosiou A \& Ashworth A 2002 MAP kinase phosphatases. Genome Biology 3 REVIEWS3009.

Tsai SY, Carlstedt-Duke J, Weigel NL, Dahlman K, Gustafsson JÅ, Tsai MJ \& O'Malley BW 1988 Molecular interactions of steroid hormone receptor with its enhancer element: evidence for receptor dimer formation. Cell 55 361-369.

Wu W, Pew T, Zou M, Pang D \& Conzen SD 2005 Glucocorticoid receptor-induced MAPK phosphatase-1 (MPK-1) expression inhibits paclitaxel-associated MAPK activation and contributes to breast cancer cell survival. Journal of Biological Chemistry $\mathbf{2 8 0}$ $4117-4124$.

Zhao Q, Shepherd EG, Manson ME, Nelin LD, Sorokin A \& Liu Y 2005 The role of mitogen-activated protein kinase phosphatase-1 in the response of alveolar macrophages to lipopolysaccharide: attenuation of proinflammatory cytokine biosynthesis via feedback control of p38. Journal of Biological Chemistry 280 8101-8108.

Received in final form 26 June 2008

Accepted 5 August 2008

Made available online as an Accepted Preprint 5 August 2008 